\title{
Impact of Multi-GNSS on Positioning Accuracy and Multipath Errors in High-Precision Single-Epoch Solutions - A Case Study in Ningbo China
}

\author{
Lawrence Lau ${ }^{1}$, Hiroaki Tateshita ${ }^{2}$ and Kazutoshi Sato ${ }^{2}$ \\ ${ }^{I}$ (University of Nottingham Ningbo China) \\ 2 (Japan Aerospace Exploration Agency (JAXA)) \\ (E-mail: lawrence.lau@nottingham.edu.cn)
}

\begin{abstract}
Real-Time Kinematic (RTK) Global Positioning System (GPS) carrier phase-based precise positioning has been widely using in geodesy and surveying applications, and other high accuracy positioning and navigation applications in the last two decades. More Global Navigation Satellite Systems (GNSS) are being developed and it is usually expected that combining GNSS will have a positive impact on positioning accuracy. This paper describes a case study carried out at Ningbo in China on the impact of multi-GNSS on RTK single epoch solutions. Both GPS and GLONASS are fully operational now. Moreover, the Quasi-Zenith Satellite System (QZSS) can be observed at Ningbo. Currently, only one QZSS satellite "MICHIBIKI" is operational. This paper carries out an early assessment of the impact of QZSS on GPS and GLONASS single-epoch high precision positioning (i.e., single-epoch positioning accuracy assessment) and investigates the multipath errors in the GPS, GLONASS and QZSS multi-frequency data.
\end{abstract}

\section{KEYWORDS}

1. Multi-GNSS. 2. QZSS. 3. Single-epoch positioning accuracy assessment 4. Multipath errors

Submitted: 2 September 2014. Accepted: 12 February 2015. First published online: 31 March 2015.

1. INTRODUCTION. Full Operational Capability (FOC) of the Global Positioning System (GPS) was declared in 1995. GPS carrier phase-based precise positioning is widely used in attitude and orbit determination, geodesy, deformation monitoring, survey applications, Real-Time Kinematic (RTK) positioning for machine guidance, and other highaccuracy applications. Nowadays, many countries have developed or are developing their own satellite navigation systems for global positioning; the generic term for a satellite navigation system is Global Navigation Satellite System (GNSS). Scientific and research 
groups have been studying the benefits of combining GNSS systems and promoting the use of multi-frequency and multi-GNSS data for applications; examples of the research groups are the International Association of Geodesy (IAG) Working Group 4.5.4: Data Processing of Multiple GNSS Signals, the International GNSS Service (IGS) Multi-GNSS Experiment (MGEX) and the Japan Aerospace Exploration Agency (JAXA) Multi-GNSS Asia (MGA). Advantages of combining the inter-operable and inter-compatible GNSS systems are anticipated. One of the benefits of using multi-frequency and multi-GNSS data is the improvement in reliability and efficiency of ambiguity resolution (Li et al., 2010; O’Keefe et al., 2009). Moreover, Lau (2004) and Lau and Cross (2007a, 2008) have developed new algorithms to mitigate carrierphase multipath errors with multi-frequency and multi-GNSS data. Schönemann et al. (2011) proposed to use un-differenced and non-linear combined multi-GNSS and multi-signal data to estimate the signal specific Un-calibrated Signal Delay (USD); USD is less stable when it is differenced and linear combined. In general, multi-GNSS improves positioning continuity, accuracy, efficiency, availability and reliability (Rizos, 2008).

The US GPS is being modernised, the Russian GLONASS has been revitalised and will be modernised, and the Chinese Compass/BeiDou III and the European Galileo are scheduled to provide global-coverage positioning starting in 2020. Strictly speaking, in terms of global positioning capability, they are the four known GNSSs now. In addition to the GNSS satellites, there are satellites of Space Based Augmentation Systems (SBASs) and Regional Navigation Satellite Systems (RNSSs) to enhance the regional positioning performance. The current SBASs are the US Wide Area Augmentation System (WAAS), the European Geostationary Navigation Overlay Service (EGNOS), the Japanese Multi-functional Satellite Augmentation System (MSAS), and the Indian GPS Aided Geo Augmented Navigation (GAGAN) system. China's BeiDou I/II and the Indian Regional Navigational Satellite System (IRNSS) are RNSSs. Clark (2013) classifies the Japanese QZSS as a SBAS, however, the authors of this article think that QZSS has a great potential to become a RNSS because QZSS has positioning measurements in signals and it will have three more satellites by 2017 and maybe more satellites later. The investigations described in this paper are part of the Japanese Aerospace Exploration Agency (JAXA) Multi-GNSS Joint Experiment and data from GPS, GLONASS and QZSS are used in this case study.

GPS and GLONASS have been operating for decades, however, QZSS is relatively new to GNSS users. A brief introduction of QZSS is given below for completeness. The QZSS consists of a multiple number of satellites that fly in the orbit passing through the near zenith over Japan. By using almost the same positioning signals as the current GPS signals as well as the new GPS signals, which are under development in the US, the system enables us to have better positioning availability in mountainous and urban regions in Japan as illustrated in Figure 1. Furthermore, the QZSS aims at improving positioning accuracy of one metre to the centimetre level in stand-alone mode. In order to have at least one quasi-zenith satellite always flying near Japan's zenith, at least three satellites are necessary. The first quasi-zenith satellite "MICHIBIKI" carries out technical and application verification of the satellite as the first phase, then the verification results will be evaluated for moving to the second phase in which the QZSS system verification will be performed with three QZSS satellites.

Currently, only one QZSS satellite "MICHIBIKI" is operational. This paper makes an early assessment of the impact of QZSS on GPS and GLONASS single-epoch high 


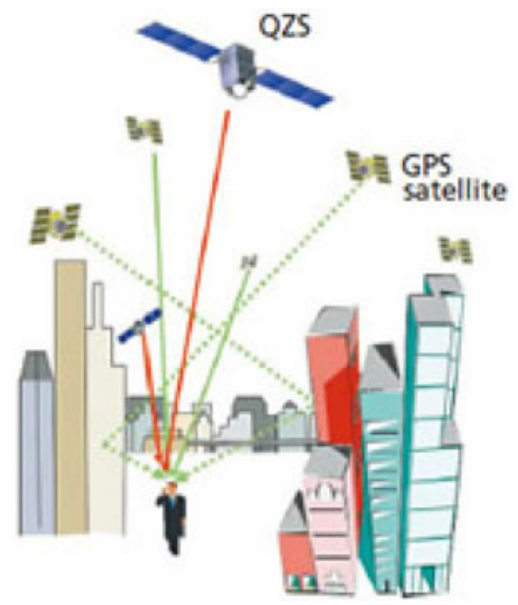

Figure 1. Assistance of QZSS for GPS positioning in high-rise urban areas (Courtesy of JAXA).

precision positioning (i.e., single-epoch positioning accuracy assessment) and investigates the multipath errors in the GPS, GLONASS and QZSS multi-frequency data. This case study was carried out at Ningbo in China; the ground track of the QZSS MICHIBIKI satellite and the location of Ningbo are shown in Figure 2. Ningbo is located in an excellent GNSS and RNSS coverage region; it is in the region of the highest predicted number of visible navigation satellites in 2018 as shown in Figure 3. Experimental setup, data sets and constellation scenarios used for the assessment are described in Section 2. Processing results of the test scenarios in positioning accuracy assessment of a data set collected in a good environment are described and analysed in Section 3, results of two data sets collected in difficult environments are described and analysed in Section 4. Section 5 describes and analyses the results of multipath effect on the signals of GPS, GLONASS and QZSS. Concluding remarks and further research are given in Section 6.

2. TEST DESIGN AND DATA COLLECTION. Two permanent reference stations were built on the roof of the Science and Engineering Building of the Ningbo campus, the distance between the two stations is about $10 \mathrm{~m}$. The reference stations are shown in Figure 4, two Leica AR25 3D choke-ring antennas (the antenna on the north pillar was replaced with AR20 in July 2013) are connected to two signal splitters in the GNSS Lab on the top floor of the Science and Engineering Building. Two JAXA loan JAVAD SIGMA-G3 T receivers were connected to the two signal splitters. This $10 \mathrm{~m}$ short baseline is used to assess the positioning accuracy of the selected GNSS constellations in a good environment (i.e., a low multipath environment). The data set used in this assessment was collected from about UTC 7:00 to 17:00 on 18 September 2013. Results and analysis of this assessment are described in Section 3.

Two short baselines on the university campus were selected for assessing the positioning accuracy of the selected GNSS constellations in difficult environments (i.e., severe multipath environments). The reference station of the two baselines is one of the permanent reference stations on our campus, it is the north pillar and is named 


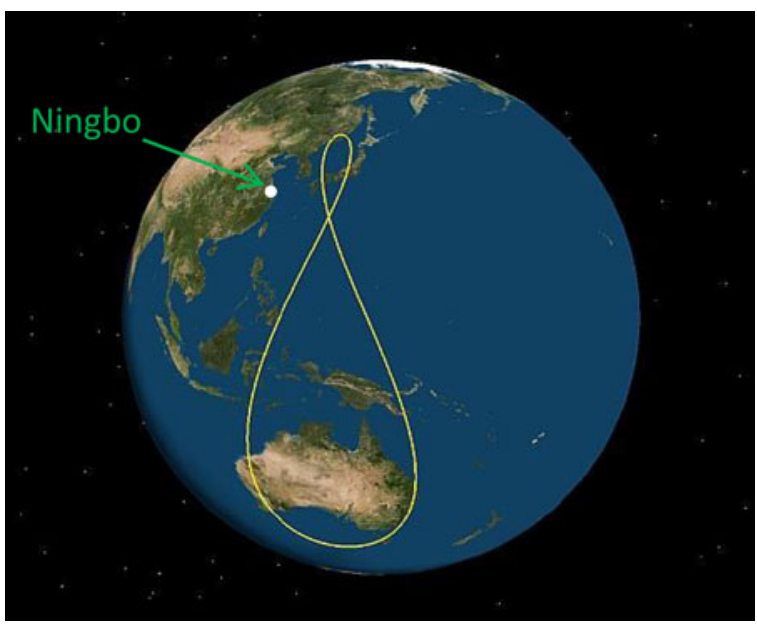

Figure 2. The ground track of the QZSS MICHIBIKI satellite and the location of Ningbo (Courtesy of JAXA).

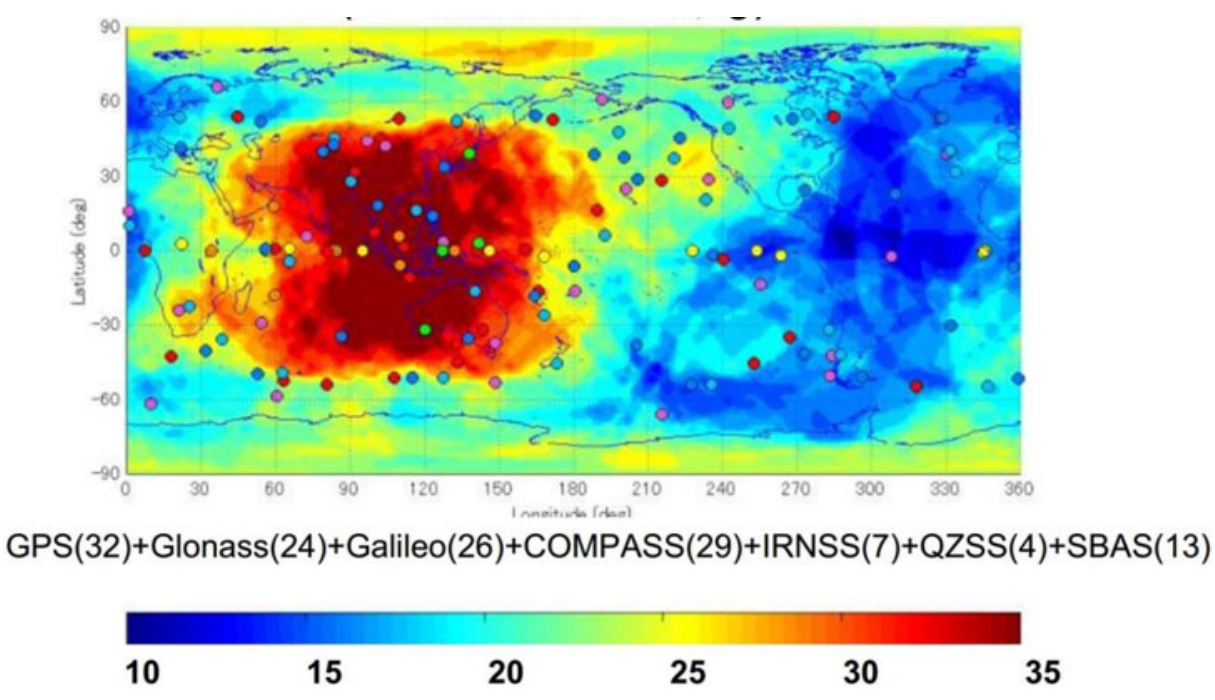

Figure 3. Predicted number of visible (elevation angle $>30^{\circ}$ ) global and regional navigation satellites in 2018 (Courtesy of JAXA).

UNNC01; the far one shown in Figure 4. Rover stations of the two baselines are UNNC25 and UNNC26 on the campus. As shown in Figures 5 and 6, there are many inclined reflective surfaces such as solar panels and metallic pipes near the two rover stations; inclined surfaces can cause multipath effect with high elevation satellites. The locations of the two rover stations UNNC25 and UNNC26 on the campus are shown on the university map in Figure 7; the two baselines are about $400 \mathrm{~m}$ long. Observation time and QZSS availability of the data sets are shown in 


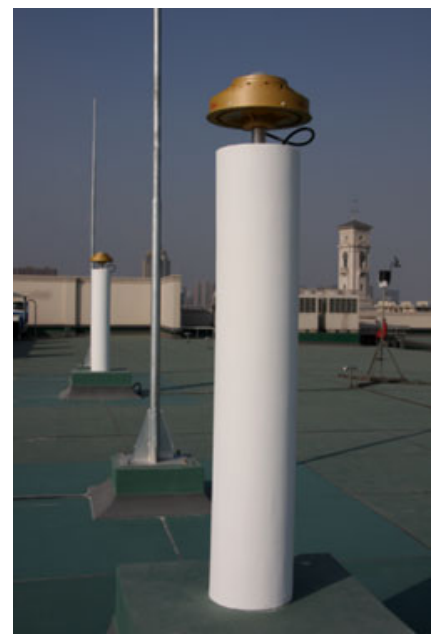

Figure 4. The reference stations in the University of Nottingham Ningbo China campus.

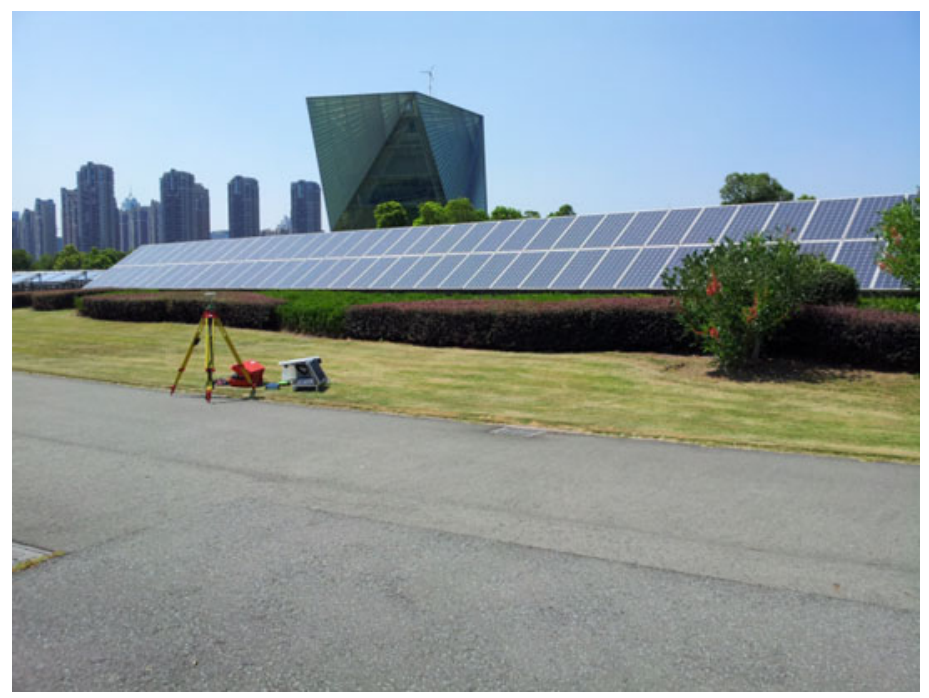

Figure 5. The environment of the rover station UNNC25 in the campus.

Table 1, only observation time with QZSS data is processed. Results and analysis of this assessment are described in Section 4. The two short baselines are also used to investigate the multipath effect of the signals of the selected GNSS constellations; results and analysis of this multipath investigation are described in Section 5. Note that no longer baselines are used in this paper because this paper does not aim to investigate the effect of ionosphere, troposphere, and satellite orbit errors on positioning.

RTKLIB is recommended by JAXA for data processing in the Multi-GNSS Joint Experiment. All results shown in Sections 3 and 4 are processed by RTKLIB (Version 


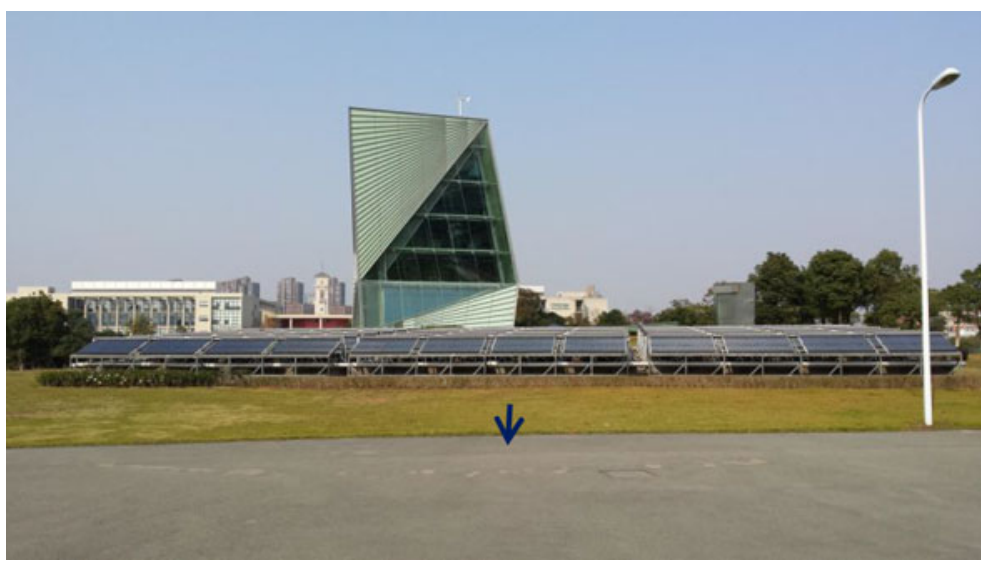

Figure 6. The environment of the rover station UNNC26 in the campus.

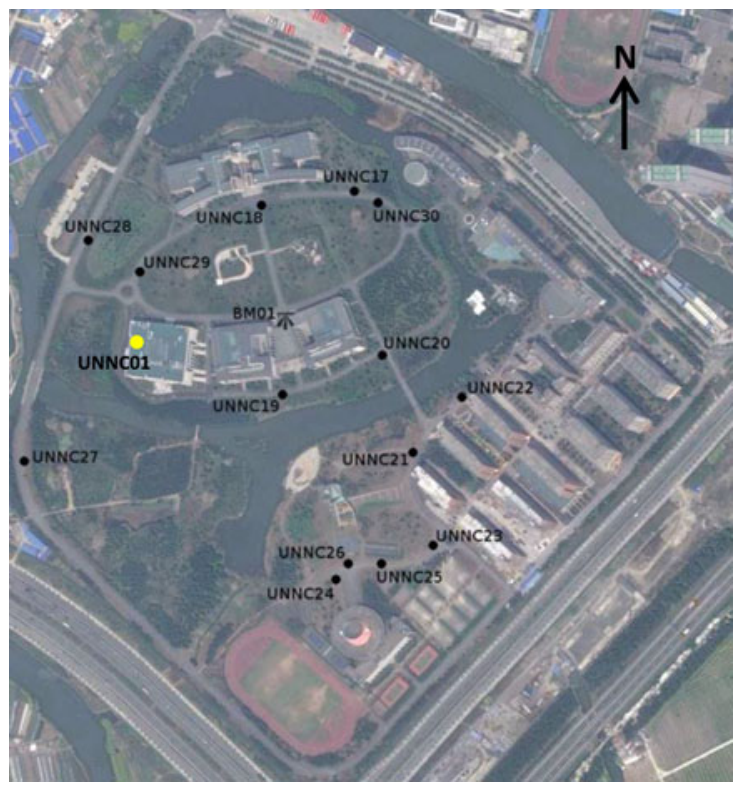

Figure 7. Location of UNNC01, UNNC25 and UNNC26 on the university campus.

Table 1. Observation information of the two short-baseline data sets collected on the campus on 30 July 2013.

\begin{tabular}{lllll}
\hline Station & Obs. time & Obs. period & Time with QZSS in view & $\begin{array}{l}\text { QZSS elevation } \\
\text { angle }\end{array}$ \\
\hline UNNC25 & $01: 19: 50-03: 29: 36$ & $\sim 2 \mathrm{hr} 10 \mathrm{~min}$ & 01:34:07-03:29:36 & $10^{\circ}-22 \cdot 3^{\circ}$ \\
UNNC26 & $03: 44: 57-05: 54: 06$ & $\sim 2 \mathrm{hr} 10 \mathrm{~min}$ & Whole period & $24^{\circ}-48^{\circ}$ \\
\hline
\end{tabular}


Table 2. RMS errors in Northing, Easting, Height and 3D vector of the baseline UNNC01-UNNC02.

\begin{tabular}{lcccc}
\hline GNSS constellation combination & $\begin{array}{l}\text { Northing } \\
\text { RMS error } \\
(\mathrm{mm})\end{array}$ & $\begin{array}{l}\text { Easting } \\
\text { RMS error } \\
(\mathrm{mm})\end{array}$ & $\begin{array}{l}\text { Height } \\
\text { RMS error } \\
(\mathrm{mm})\end{array}$ & $\begin{array}{l}\text { 3D vector } \\
\text { RMS error } \\
(\mathrm{mm})\end{array}$ \\
\hline GPS & $0 \cdot 35$ & $0 \cdot 36$ & $1 \cdot 63$ & $1 \cdot 71$ \\
GPS + GLONASS & $0 \cdot 28$ & $0 \cdot 26$ & $2 \cdot 72$ & $2 \cdot 75$ \\
GPS + QZSS & $0 \cdot 20$ & $0 \cdot 31$ & $1 \cdot 65$ & $1 \cdot 69$ \\
GPS + GLONASS + QZSS & $0 \cdot 21$ & $0 \cdot 24$ & $2 \cdot 76$ & $2 \cdot 78$ \\
\hline
\end{tabular}

Table 3. Percentage improvement in Northing, Easting, Height and 3D vector of baseline UNNC01-UNNC02.

\begin{tabular}{lcccr}
\hline & $\begin{array}{l}\text { \% improvement } \\
\text { in Northing }\end{array}$ & $\begin{array}{l}\% \text { improvement } \\
\text { in Easting }\end{array}$ & $\begin{array}{l}\% \text { improvement } \\
\text { in Height }\end{array}$ & $\begin{array}{l}\% \text { improvement } \\
\text { in 3D vector }\end{array}$ \\
\hline GPS & - & - & - & - \\
GPS + GLONASS & $20 \cdot 0$ & $27 \cdot 8$ & $-66 \cdot 9$ & $-61 \cdot 0$ \\
GPS + QZSS & $42 \cdot 9$ & $13 \cdot 9$ & $-1 \cdot 2$ & $0 \cdot 9$ \\
GPS + GLONASS + QZSS & $40 \cdot 0$ & $33 \cdot 3$ & $-69 \cdot 3$ & $-62 \cdot 9$ \\
\hline
\end{tabular}

2.4.2) in static single-epoch mode. RTKLIB is an open source program package for standard and precise positioning with GNSS including GPS, GLONASS, Galileo, QZSS, BeiDou and SBAS (RTKLIB, 2014). Four scenarios of GNSS constellations are tested in this paper: i) GPS only, ii) combining GPS and GLONASS, iii) combining GPS and QZSS, and iv) combining GPS, GLONASS and QZSS.

\section{RESULTS OF THE POSITIONING ACCURACY ASSESSMENT IN A} GOOD ENVIRONMENT. Since the rover station UNNC02 of the roof baseline is known, Root Mean Square (RMS) error is used to assess the positioning accuracy of the four GNSS constellation combinations. RMS errors in Northing, Easting and Height components and 3D vector of the four GNSS constellation combinations are shown in Table 2. Percentage improvement of GNSS constellation combinations on Northing, Easting, Height and 3D vector RMS errors are obtained by comparing with the GPS system, and the results are shown in Table 3 (positive value means improvement; negative value means deterioration). According to the $3 \mathrm{D}$ vector results, the GNSS constellation combinations involving GLONASS show deteriorations when comparing with GPS alone. This is because the introduction of GLONASS to GPS alone and GPS + QZSS increases the number of wrong ambiguity fixes, leading to significant deterioration in height but improvements in horizontal components (see the results of GPS + GLONASS and GPS + GLONASS + QZSS in Table 3). Introduction of QZSS to GPS shows improvement in horizontal components but a very slight (about $1 \%$ ) improvement in the 3D vector, which is probably due to the limited impact of a single QZSS satellite and the satellite geometry at Ningbo (see Figure 2). However, slightly more significant improvement may be seen if the International GNSS Service (IGS) ANTenna EXchange format (ANTEX) file includes the QZSS transmitting and receiving antenna calibration.

Since the coordinates of the two rover stations are known, "true" errors/residuals of observations can be calculated. RMS errors of GPS L1, L2 and L5 carrier phase 
Table 4. RMS errors of GPS L1, L2 and L5 carrier phase observations of the baseline UNNC01-UNNC02.

\begin{tabular}{|c|c|c|c|c|}
\hline PRN & $\begin{array}{l}\text { L1 RMS } \\
\text { error }(\mathrm{mm})\end{array}$ & $\begin{array}{l}\text { L2 RMS } \\
\text { error (mm) }\end{array}$ & $\begin{array}{l}\text { L5 RMS } \\
\text { error }(\mathrm{mm})\end{array}$ & Remark \\
\hline 02 & $4 \cdot 7$ & $4 \cdot 5$ & - & Block IIR \\
\hline 04 & $4 \cdot 1$ & $4 \cdot 6$ & - & Block IIA \\
\hline 05 & 4.9 & $4 \cdot 6$ & - & Block IIR-M \\
\hline 07 & $6 \cdot 9$ & $7 \cdot 3$ & - & Block IIR-M \\
\hline 08 & $5 \cdot 8$ & $7 \cdot 8$ & - & Block IIA \\
\hline 09 & $5 \cdot 2$ & 6.9 & - & Block IIA \\
\hline 10 & $5 \cdot 8$ & $4 \cdot 4$ & - & Block IIA \\
\hline 12 & $5 \cdot 9$ & $5 \cdot 3$ & - & Block IIR-M \\
\hline 13 & $5 \cdot 5$ & $6 \cdot 7$ & - & Block IIR \\
\hline 14 & $5 \cdot 1$ & 4.9 & - & Block IIR \\
\hline 15 & $5 \cdot 1$ & $4 \cdot 6$ & - & Block IIR-M \\
\hline 17 & $5 \cdot 4$ & $4 \cdot 5$ & - & Block IIR-M \\
\hline 18 & $7 \cdot 4$ & $5 \cdot 3$ & - & Block IIR \\
\hline 20 & $5 \cdot 8$ & $6 \cdot 9$ & - & Block IIR \\
\hline 21 & $5 \cdot 9$ & $5 \cdot 6$ & - & Block IIR \\
\hline 22 & $7 \cdot 1$ & $4 \cdot 1$ & - & Block IIR \\
\hline 23 & $5 \cdot 8$ & $7 \cdot 1$ & - & Block IIR \\
\hline 24 & $6 \cdot 1$ & $5 \cdot 5$ & $3 \cdot 5$ & Block IIF \\
\hline 25 & $5 \cdot 4$ & $5 \cdot 1$ & $4 \cdot 6$ & Block IIF \\
\hline 26 & $6 \cdot 1$ & $5 \cdot 0$ & - & Block IIA \\
\hline 28 & $4 \cdot 7$ & $6 \cdot 6$ & - & Block IIR \\
\hline 29 & 4.9 & $5 \cdot 7$ & - & Block IIR-M \\
\hline 31 & $5 \cdot 2$ & $4 \cdot 0$ & - & Block IIR-M \\
\hline \multirow[t]{2}{*}{32} & $15 \cdot 1$ & $19 \cdot 1$ & - & $\begin{array}{l}\text { Block IIA Only have } \\
1335 \text { obs. In } 12 \text { hours; } \\
\text { low elevation satellite }\end{array}$ \\
\hline & $\begin{array}{l}\text { L1 carrier } \\
\text { phase }\end{array}$ & $\begin{array}{l}\text { L2 carrier } \\
\text { phase }\end{array}$ & $\begin{array}{l}\text { L5 carrier } \\
\text { phase }\end{array}$ & \\
\hline $\begin{array}{l}\text { Overall RMS } \\
\text { error (mm) }\end{array}$ & $5 \cdot 7$ & $5 \cdot 4$ & $3 \cdot 9$ & \\
\hline
\end{tabular}

observations of satellites in the baseline UNNC01-UNNC02 are shown in Table 4 and the overall RMS errors of carrier phases (i.e., L1, L2 and L5 carriers) are shown at the bottom of Table 4 . Wrong ambiguity fixes are excluded in this analysis because the ambiguity resolution method is software dependent, whereas an aim of this paper is to assess the impact of signals and constellations on positioning accuracy. According to the results in Table 4, the type of satellites (i.e., Block IIA, Block IIR, Block IIR$\mathrm{M}$, and Block IIF) does not show significant difference in RMS error per frequency. The overall RMS errors of L1 and L2 carriers are similar, but the L5 carrier has smaller overall RMS error than L1 and L2 carriers (about 30\% less). This may show that the signal/data quality of L5 is better than those of L1 and L2.

RMS errors of GLONASS L1-band and L2-band carrier phase observations of satellites in the baseline UNNC01-UNNC02 are shown in Table 5 and the overall RMS errors of carrier phases (i.e., L1-band and L2-band carriers) are shown at the bottom of Table 5. The overall RMS errors of L1-band and L2-band carriers are very similar, which may show that the signal/data qualities of L1-band and L2-band carriers are similar. 
Table 5. RMS errors of GLONASS L1 and L2 carrier phase observations of the baseline UNNC01-UNNC02.

\begin{tabular}{|c|c|c|c|}
\hline PRN/SV ID & L1 RMS error (mm) & L2 RMS error (mm) & Remark \\
\hline 1 & $3 \cdot 8$ & $3 \cdot 4$ & GLONASS-M \\
\hline 2 & $3 \cdot 8$ & $3 \cdot 5$ & GLONASS-M \\
\hline 3 & $3 \cdot 0$ & $3 \cdot 3$ & GLONASS-M \\
\hline 4 & $4 \cdot 0$ & $3 \cdot 6$ & GLONASS-M \\
\hline 5 & $4 \cdot 3$ & $3 \cdot 5$ & GLONASS-M \\
\hline 6 & $4 \cdot 1$ & $2 \cdot 9$ & GLONASS-M \\
\hline 7 & $3 \cdot 5$ & $3 \cdot 7$ & GLONASS-M \\
\hline 8 & $4 \cdot 1$ & $4 \cdot 1$ & GLONASS-M \\
\hline 9 & $2 \cdot 7$ & $3 \cdot 0$ & GLONASS-M \\
\hline 10 & $2 \cdot 6$ & $3 \cdot 5$ & GLONASS-M \\
\hline 12 & $6 \cdot 7$ & $5 \cdot 4$ & GLONASS-M \\
\hline 13 & $3 \cdot 8$ & $4 \cdot 5$ & GLONASS-M \\
\hline 14 & $5 \cdot 4$ & $4 \cdot 7$ & GLONASS-M \\
\hline 15 & $5 \cdot 0$ & $3 \cdot 9$ & GLONASS-M \\
\hline 16 & $4 \cdot 9$ & $2 \cdot 9$ & GLONASS-M \\
\hline 17 & $4 \cdot 6$ & $3 \cdot 8$ & GLONASS-M \\
\hline 18 & $3 \cdot 4$ & $3 \cdot 6$ & GLONASS-M \\
\hline 19 & $2 \cdot 9$ & $3 \cdot 4$ & GLONASS-M \\
\hline 20 & $5 \cdot 6$ & $4 \cdot 6$ & GLONASS-M \\
\hline 21 & $11 \cdot 8$ & $7 \cdot 0$ & GLONASS-M \\
\hline 23 & $3 \cdot 8$ & $4 \cdot 2$ & GLONASS-M \\
\hline \multirow[t]{2}{*}{24} & $2 \cdot 8$ & $2 \cdot 9$ & GLONASS-M \\
\hline & L1 carrier phase & L2 carrier phase & \\
\hline $\begin{array}{l}\text { Overall RMS } \\
\text { error }(\mathrm{mm})\end{array}$ & $4 \cdot 1$ & $3 \cdot 7$ & \\
\hline
\end{tabular}

Table 6. RMS errors of L1, L2 and L5 signals of the QZSS MICHIBIKI/J1 of the baseline UNNC01UNNC02.

\begin{tabular}{lccc}
\hline & L1 carrier phase & L2 carrier phase & L5 carrier phase \\
\hline RMS error $(\mathrm{mm})$ & 5.9 & $4 \cdot 2$ & 3.8 \\
\hline
\end{tabular}

RMS errors of L1, L2 and L5 carrier phase observations of the only QZSS satellite MICHIBIKI/J1 in the baseline UNNC01-UNNC02 are shown in Table 6. The single satellite result shows that the signal/data qualities of QZZS L1 and L5 carriers are very similar to those of GPS (see Tables 4 and 6). Similar to the above GPS results, the signal/data quality of QZZS L5 carrier is better than that of L1 and L2 carriers (less obvious when comparing with QZSS L2).

\section{RESULTS OF THE POSITIONING ACCURACY ASSESSMENT IN} DIFFICULT ENVIRONMENTS. RMS errors in Northing, Easting and Height components and 3D vector of the four GNSS constellation combinations over the UNNC01-UNNC25 baseline are shown in Table 7; the corresponding percentages of fixed and floating solutions are given in Table 8. Percentage improvement of GNSS constellation combinations on Northing, Easting, Height and 3D vector RMS errors are obtained by comparing with the GPS system; the results are shown 
Table 7. RMS errors in Northing, Easting, Height and 3D vector of fixed solutions in baseline UNNC01-UNNC25.

\begin{tabular}{lcccc}
\hline $\begin{array}{l}\text { GNSS constellation } \\
\text { combination }\end{array}$ & $\begin{array}{l}\text { Northing RMS } \\
\text { error (mm) }\end{array}$ & $\begin{array}{l}\text { Easting RMS } \\
\text { error (mm) }\end{array}$ & $\begin{array}{l}\text { Height RMS } \\
\text { error (mm) }\end{array}$ & $\begin{array}{l}\text { 3D vector } \\
\text { RMS error } \\
(\mathrm{mm})\end{array}$ \\
\hline GPS & $1 \cdot 80$ & $1 \cdot 17$ & $4 \cdot 42$ & $4 \cdot 91$ \\
GPS + GLONASS & $2 \cdot 59$ & 1.34 & $5 \cdot 71$ & 6.41 \\
GPS + QZSS & $2 \cdot 39$ & 1.52 & $7 \cdot 13$ & 7.67 \\
GPS + GLONASS + QZSS & 3.09 & 1.80 & 7.94 & 8.71 \\
\hline
\end{tabular}

Table 8. Percentage of fixed and float solutions in the baseline UNNC01-UNNC25.

\begin{tabular}{lcc}
\hline GNSS constellation combination & Fixed solution (\%) & Float solution (\%) \\
\hline GPS & $96 \cdot 5$ & $3 \cdot 5$ \\
GPS + GLONASS & $77 \cdot 0$ & $23 \cdot 0$ \\
GPS + QZSS & $94 \cdot 5$ & $5 \cdot 5$ \\
GPS + GLONASS + QZSS & $70 \cdot 5$ & $29 \cdot 5$ \\
\hline
\end{tabular}

Table 9. Percentage improvement on Northing, Easting, Height and 3D vector of baseline UNNC01-UNNC25.

\begin{tabular}{lcccc}
\hline & $\begin{array}{c}\text { \% improvement } \\
\text { in Northing }\end{array}$ & $\begin{array}{l}\text { \% improvement } \\
\text { in Easting }\end{array}$ & $\begin{array}{l}\text { \% improvement } \\
\text { in Height }\end{array}$ & $\begin{array}{l}\% \text { improvement } \\
\text { in 3D vector }\end{array}$ \\
\hline GPS & - & - & - & - \\
GPS + GLONASS & $-43 \cdot 9$ & $-14 \cdot 5$ & $-29 \cdot 2$ & $-30 \cdot 5$ \\
GPS + QZSS & $-32 \cdot 8$ & $-29 \cdot 9$ & $-61 \cdot 3$ & $-56 \cdot 1$ \\
GPS + GLONASS + QZSS & $-71 \cdot 7$ & $-53 \cdot 8$ & $-79 \cdot 6$ & $-77 \cdot 2$ \\
\hline
\end{tabular}

in Table 9 (positive value means improvement; negative value means deterioration). Again, the GNSS constellation combinations involving GLONASS show significant deterioration in positioning accuracy and lower ambiguity resolution success rate when comparing with GPS alone. Introduction of QZSS to GPS slightly reduces the ambiguity resolution success rate (about $2 \%$ ) but significantly deteriorates the positioning accuracy (about 56\%). The results show that combining GLONASS and/or QZSS with GPS increases the RMS errors and deteriorate the positioning accuracy in this data set, which may be due to more satellites having multipath errors in the difficult environment. Multipath effect in signals is discussed in Section 5.

RMS errors in carrier phases of GPS satellites over the UNNC01-UNNC25 baseline are presented in Table 10, the overall RMS errors of carrier phases being shown at the bottom of Table 10. By comparing Table 10 with Table 4, this data set collected in a difficult environment has about $44 \%, 156 \%$ and $131 \%$ increments in the overall RMS errors of L1, L2 and L5 carrier phases, respectively. From Table 10, L2 carrier phase is affected the most in this data set. No obvious differences in RMS errors can be found with different GPS satellite types. 
Table 10. RMS errors of GPS L1, L2 and L5 carrier phase observations of the baseline UNNC01-UNNC25.

\begin{tabular}{|c|c|c|c|c|}
\hline PRN & $\begin{array}{l}\text { L1 RMS } \\
\text { error (mm) }\end{array}$ & $\begin{array}{l}\text { L2 RMS } \\
\text { error }(\mathrm{mm})\end{array}$ & $\begin{array}{l}\text { L5 RMS } \\
\text { error (mm) }\end{array}$ & Remark \\
\hline 03 & $7 \cdot 3$ & $12 \cdot 7$ & - & Block IIA \\
\hline 06 & $7 \cdot 0$ & $12 \cdot 9$ & - & Block IIA \\
\hline 13 & $6 \cdot 7$ & $14 \cdot 6$ & - & Block IIR \\
\hline 14 & $11 \cdot 3$ & $13 \cdot 3$ & - & Block IIR \\
\hline 16 & $6 \cdot 8$ & $14 \cdot 0$ & - & Block IIR \\
\hline 19 & $8 \cdot 9$ & $15 \cdot 5$ & - & Block IIR \\
\hline 20 & $13 \cdot 9$ & $14 \cdot 8$ & - & Block IIR \\
\hline 21 & $10 \cdot 6$ & $14 \cdot 7$ & - & Block IIR \\
\hline 23 & $6 \cdot 7$ & $12 \cdot 0$ & - & Block IIR \\
\hline 27 & $6 \cdot 9$ & $12 \cdot 7$ & $9 \cdot 0$ & Block IIF \\
\hline 29 & $25 \cdot 0$ & - & - & Block IIR-M \\
\hline 31 & $7 \cdot 6$ & $14 \cdot 4$ & - & Block IIR-M \\
\hline \multirow[t]{2}{*}{32} & $16 \cdot 1$ & $19 \cdot 1$ & - & Block IIA \\
\hline & $\begin{array}{l}\text { L1 carrier } \\
\text { phase }\end{array}$ & $\begin{array}{l}\text { L2 carrier } \\
\text { phase }\end{array}$ & $\begin{array}{l}\text { L5 carrier } \\
\text { phase }\end{array}$ & \\
\hline $\begin{array}{l}\text { Overall RMS } \\
\text { error (mm) }\end{array}$ & $8 \cdot 2$ & $13 \cdot 8$ & $9 \cdot 0$ & \\
\hline
\end{tabular}

Table 11. RMS errors of GLONASS L1 and L2 carrier phase observations of the baseline UNNC01-UNNC25.

\begin{tabular}{lccc}
\hline PRN/SV ID & $\begin{array}{c}\text { L1 RMS } \\
\text { error }(\mathrm{mm})\end{array}$ & $\begin{array}{c}\text { L2 RMS } \\
\text { error }(\mathrm{mm})\end{array}$ & Remark \\
\hline 5 & $14 \cdot 3$ & $11 \cdot 0$ & GLONASS-M \\
6 & $8 \cdot 5$ & $11 \cdot 2$ & GLONASS-M \\
7 & $7 \cdot 3$ & $8 \cdot 6$ & GLONASS-M \\
9 & $8 \cdot 5$ & $14 \cdot 6$ & GLONASS-M \\
14 & $6 \cdot 6$ & $7 \cdot 6$ & GLONASS-M \\
15 & $5 \cdot 9$ & $5 \cdot 6$ & GLONASS-M \\
16 & $5 \cdot 4$ & $5 \cdot 9$ & GLONASS-M \\
17 & $7 \cdot 2$ & $13 \cdot 9$ & GLONASS-M \\
18 & $5 \cdot 0$ & $10 \cdot 6$ & GLONASS-M \\
19 & $6 \cdot 1$ & $14 \cdot 9$ & \\
\hline & L1 carrier & L2 carrier & \\
\hline Overall RMS & phase & $10 \cdot 9$ & \\
error (mm) & $7 \cdot 1$ & & \\
\hline
\end{tabular}

RMS errors in carrier phases of GLONASS satellites over the UNNC01-UNNC25 baseline are presented in Table 11, the overall RMS errors of carrier phases shown at the bottom of Table 11. By comparing Table 11 with Table 5, this data set collected in a difficult environment has about $73 \%$ and $195 \%$ increments in the overall RMS errors of L1-band and L2-band carrier phases, respectively.

RMS errors in carrier phases of the QZSS MICHIBIKI/J1 satellite over the UNNC01-UNNC25 baseline are presented in Table 12. By comparing Table 12 with Table 6, this data set collected in a difficult environment has about 
Table 12. RMS errors of L1, L2 and L5 signals of the QZSS MICHIBIKI/J1 of the baseline UNNC01-UNNC25.

\begin{tabular}{lccc}
\hline & L1 carrier phase & L2 carrier phase & L5 carrier phase \\
\hline RMS error $(\mathrm{mm})$ & $12 \cdot 3$ & $14 \cdot 0$ & $9 \cdot 0$ \\
\hline
\end{tabular}

Table 13. RMS errors in Northing, Easting, Height and 3D vector of fixed solutions in the baseline UNNC01-UNNC26.

\begin{tabular}{lrccc}
\hline $\begin{array}{l}\text { GNSS constellation } \\
\text { combination }\end{array}$ & $\begin{array}{l}\text { Northing RMS } \\
\text { error }(\mathrm{mm})\end{array}$ & $\begin{array}{l}\text { Easting RMS } \\
\text { error }(\mathrm{mm})\end{array}$ & $\begin{array}{l}\text { Height RMS } \\
\text { error }(\mathrm{mm})\end{array}$ & $\begin{array}{l}\text { 3D vector RMS } \\
\text { error (mm) }\end{array}$ \\
\hline GPS & 1.57 & 1.82 & 3.00 & 3.84 \\
GPS + GLONASS & 1.65 & 1.82 & $2 \cdot 36$ & 3.40 \\
GPS + QZSS & 1.67 & 2.01 & 3.06 & 4.02 \\
GPS + GLONASS + & 1.67 & 2.03 & $2 \cdot 29$ & 3.49 \\
QZSS & & & & \\
\hline
\end{tabular}

$108 \%, 233 \%$ and $137 \%$ increments in the overall RMS errors of L1, L2 and L5 carrier phases, respectively. L5 signal has the least RMS error among the QZSS frequencies.

RMS errors in Northing, Easting and Height components and 3D vector of the four GNSS constellation combinations over the UNNC01-UNNC26 baseline are shown in Table 13, and the corresponding percentages of fixed and float solutions are given in Table 14. Percentage improvement of GNSS constellation combinations on Northing, Easting, Height and 3D vector RMS errors are obtained by comparing with the GPS system; the results are shown in Table 15. The two GNSS constellation combinations involving GLONASS show lower ambiguity resolution success rate (about 3-5\%) but improvement in positioning accuracy when comparing with GPS alone; the height component has improved significantly. Introduction of QZSS to GPS does not affect the ambiguity resolution success rate but deteriorates the positioning accuracy (about $5 \%$ in the $3 \mathrm{D}$ vector) in this data set.

RMS errors in carrier phases of GPS satellites over the UNNC01-UNNC26 baseline are presented in Table 16, the overall RMS errors of carrier phases are shown at the bottom of Table 16. By comparing Table 16 with Table 4, this data set collected in a difficult environment has about $75 \%, 80 \%$ and $103 \%$ increments in the overall RMS errors of L1, L2 and L5 carrier phases, respectively. From Table 16, the signal/data qualities of L1 and L2 carrier phases are very similar but L5 carrier phase has the best quality in this data set. Again, no obvious differences in RMS errors can be found with different GPS satellite types.

RMS errors in carrier phases of GLONASS satellites over the UNNC01-UNNC26 baseline are presented in Table 17, the overall RMS errors of carrier phases shown at the bottom of Table 17. By comparing Table 17 with Table 5, this data set collected in a difficult environment has about $88 \%$ and $114 \%$ increments in the overall RMS errors of L1-band and L2-band carrier phases, respectively. Very similar signal/data qualities of L1-band and L2-band carrier phases are found in this data set. 
Table 14. Percentage of fixed and float solutions in the baseline UNNC01-UNNC26.

\begin{tabular}{lcc}
\hline GNSS constellation combination & Fixed solution $(\%)$ & Float solution $(\%)$ \\
\hline GPS & $99 \cdot 95$ & $0 \cdot 05$ \\
GPS + GLONASS & $96 \cdot 75$ & $3 \cdot 25$ \\
GPS + QZSS & $99 \cdot 95$ & $0 \cdot 05$ \\
GPS + GLONASS + QZSS & $95 \cdot 47$ & $4 \cdot 53$ \\
\hline
\end{tabular}

Table 15. Percentage improvement on Northing, Easting, Height and 3D vector of baseline UNNC01-UNNC26.

\begin{tabular}{lcccc}
\hline & $\begin{array}{l}\% \text { improvement } \\
\text { in Northing }\end{array}$ & $\begin{array}{l}\% \text { improvement } \\
\text { in Easting }\end{array}$ & $\begin{array}{l}\% \text { improvement } \\
\text { in Height }\end{array}$ & $\begin{array}{l}\% \text { improvement } \\
\text { in 3D vector }\end{array}$ \\
\hline GPS & - & - & - & - \\
GPS + GLONASS & $-5 \cdot 1$ & $0 \cdot 0$ & $21 \cdot 3$ & $-2 \cdot 0$ \\
GPS + QZSS & $-6 \cdot 4$ & $-10 \cdot 4$ & $23 \cdot 7$ & $-4 \cdot 7$ \\
GPS + GLONASS + QZSS & $-6 \cdot 4$ & $-11 \cdot 5$ & $9 \cdot 3$ \\
\hline
\end{tabular}

Table 16. RMS errors of GPS L1, L2 and L5 carrier phase observations of the baseline UNNC01-UNNC26.

\begin{tabular}{lcccc}
\hline PRN & $\begin{array}{c}\text { L1 RMS } \\
\text { error }(\mathrm{mm})\end{array}$ & $\begin{array}{c}\text { L2 RMS } \\
\text { error }(\mathrm{mm})\end{array}$ & $\begin{array}{c}\text { L5 RMS } \\
\text { error }(\mathrm{mm})\end{array}$ & Remark \\
\hline 01 & $10 \cdot 2$ & $9 \cdot 1$ & $8 \cdot 2$ & Block IIF \\
03 & $7 \cdot 8$ & $7 \cdot 0$ & - & Block IIA \\
06 & $12 \cdot 9$ & $11 \cdot 4$ & - & Block IIA \\
07 & $8 \cdot 0$ & $8 \cdot 2$ & - & Block IIR-M \\
08 & $9 \cdot 4$ & $10 \cdot 9$ & - & Block IIA \\
09 & $8 \cdot 8$ & $11 \cdot 8$ & - & Block IIA \\
11 & $7 \cdot 3$ & $7 \cdot 4$ & - & Block IIR \\
13 & $14 \cdot 5$ & $14 \cdot 3$ & - & Block IIR \\
16 & $8 \cdot 6$ & $9 \cdot 2$ & - & Block IIR \\
19 & $7 \cdot 7$ & $6 \cdot 0$ & - & Block IIR \\
23 & $11 \cdot 1$ & $12 \cdot 1$ & $7 \cdot 7$ & Block IIR \\
27 & $9 \cdot 6$ & $8 \cdot 2$ & - & Block IIF \\
28 & $13 \cdot 5$ & $11 \cdot 6$ & - & Block IIR-M \\
31 & $9 \cdot 9$ & $11 \cdot 7$ & L5 carrier & \\
\hline & L1 carrier & L2 carrier & phase & $7 \cdot 9$ \\
\hline phase & $10 \cdot 0$ & $9 \cdot 7$ & & \\
\hline
\end{tabular}

RMS errors in carrier phases of the QZSS MICHIBIKI/J1 satellite over the UNNC01-UNNC26 baseline are presented in Table 18. By comparing Table 18 with Table 6, this data set collected in a difficult environment has about $37 \%, 90 \%$ and 58\% increments in the overall RMS errors of L1, L2 and L5 carrier phases, respectively. Very similar signal/data qualities of L1 and L2 carrier phases are found in this data set. The L5 signal has the least RMS error among the QZSS frequencies. 
Table 17. RMS errors of GLONASS L1 and L2 carrier phase observations of the baseline UNNC01-UNNC26.

\begin{tabular}{lccl}
\hline PRN/SV ID & L1 RMS error $(\mathrm{mm})$ & L2 RMS error $(\mathrm{mm})$ & Remark \\
\hline 9 & $4 \cdot 6$ & $4 \cdot 6$ & GLONASS-M \\
10 & $7 \cdot 2$ & $7 \cdot 5$ & GLONASS-M \\
15 & $6 \cdot 3$ & $8 \cdot 2$ & GLONASS-M \\
16 & $5 \cdot 5$ & $6 \cdot 7$ & GLONASS-M \\
18 & $10 \cdot 0$ & $9 \cdot 4$ & GLONASS-M \\
19 & $6 \cdot 3$ & $5 \cdot 8$ & GLONASS-M \\
20 & $5 \cdot 9$ & $7 \cdot 4$ & GLONASS-M \\
21 & $21 \cdot 9$ & $20 \cdot 5$ & GLONASS-M \\
\hline \multicolumn{4}{l}{ RMS error $(\mathrm{mm})$} \\
\hline
\end{tabular}

Table 18. RMS errors of L1, L2 and L5 signals of the QZSS MICHIBIKI/J1 of the baseline UNNC01-UNNC26.

\begin{tabular}{lccc}
\hline & L1 carrier phase & L2 carrier phase & L5 carrier phase \\
\hline RMS error $(\mathrm{mm})$ & $8 \cdot 1$ & $8 \cdot 0$ & $6 \cdot 0$ \\
\hline
\end{tabular}

5. INVESTIGATIONS INTO MULTIPATH ERRORS. Two data sets have been collected in difficult environments, where multipath effect is severe. The two data sets are named the UNNC01-UNNC25 baseline and the UNNC01-UNNC26 baseline as described in Sections 2 and 4. The possible reflectors in the vicinity of the antenna positions can be seen in Figures 5 and 6. The locations of the two rover stations UNNC25 and UNNC26 on the campus are shown on the university map in Figure 7; the inclined solar panels and pipes shown in Figures 5 and 6 are facing south. Sky plots of the two rover stations are shown in Figures 8 and 9; measurements of satellites in the southern sky are likely to be contaminated by multipath effect. Since the coordinates of the two rover stations are known, "true" errors/residuals of measurements can be calculated. Plots of the "true" errors/residuals of selected multipath contaminated satellites in the two data sets are shown in Figures 10 and 11, the plots clearly show the sinusoidal multipath signature of static antenna. Characteristics of carrier-phase multipath errors can be found in Lau and Cross $(2006,2007 b)$. As multipath effect is frequency dependent, multipath errors in all observing frequencies are analysed. By performing Time Fast Fourier Transform (TFFT) analysis on the multipath "signals", the amplitudes and frequencies of multipath "signals" are obtained. The maximum multipath errors in the carrier frequencies of the multipath contaminated GNSS satellites in the data sets of UNNC01-UNNC25 and UNNC01-UNNC26 baselines are given in Tables 19 and 20, respectively. It is assumed that multipath effect in the reference station UNNC01 is negligible, the main multipath error source is from the reflectors around the two rover stations UNNC25 and UNNC26.

According to the numbers of multipath contaminated satellites and the amplitudes of the maximum multipath errors in GNSS frequencies in Tables 19 and 20, multipath effect is more severe at the rover station UNNC25. By considering the rover station 


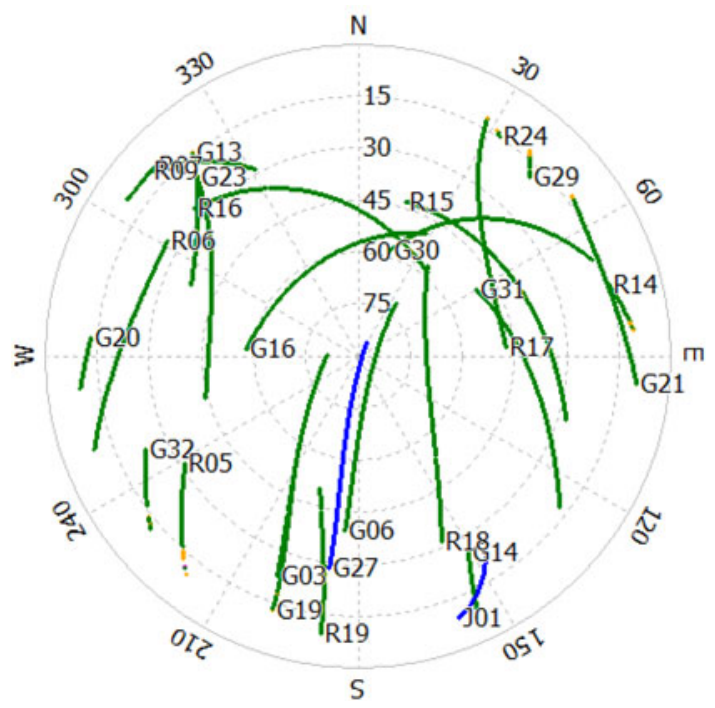

Figure 8. Sky plot of the data set collected at UNNC25.

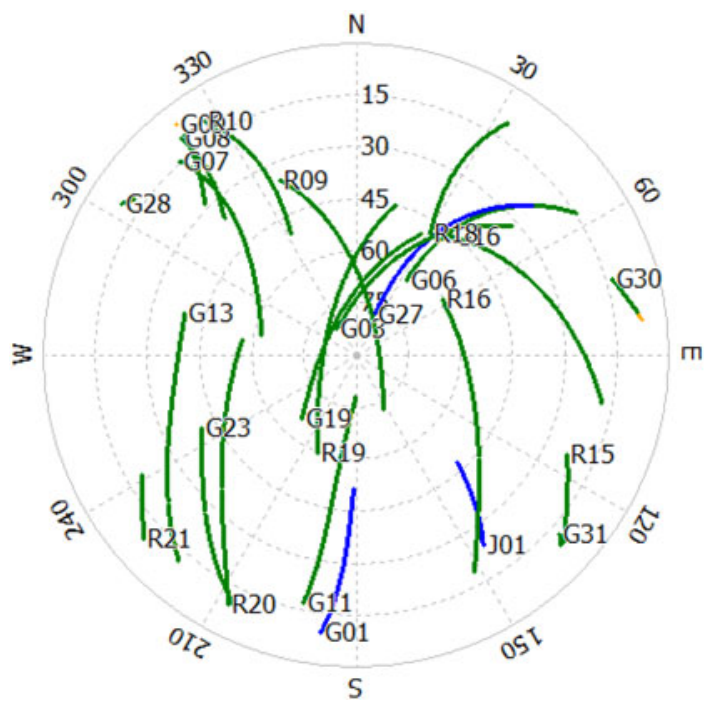

Figure 9. Sky plot of the data set collected at UNNC26.

UNNC25 results following, multipath effect is greatest on the GPS L2 frequency and least on the L5 frequency. Similar results are found in QZSS. Nevertheless, the maximum multipath error in QZSS L5 is smaller than that in GPS L5 in this data set (see Table 19). On the other hand, multipath effect on GLONASS L1 is less than that on GLONASS L2. Moreover, the results show that GLONASS L1 has better performance than GPS L1 in the multipath environment (see Table 19). All 


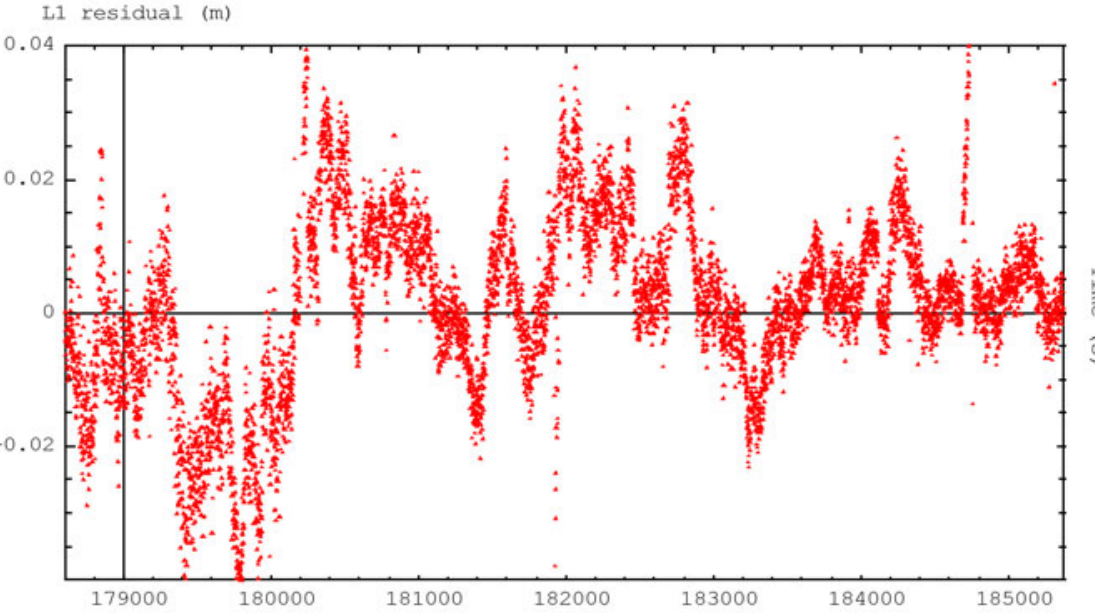

L2 residual (m)

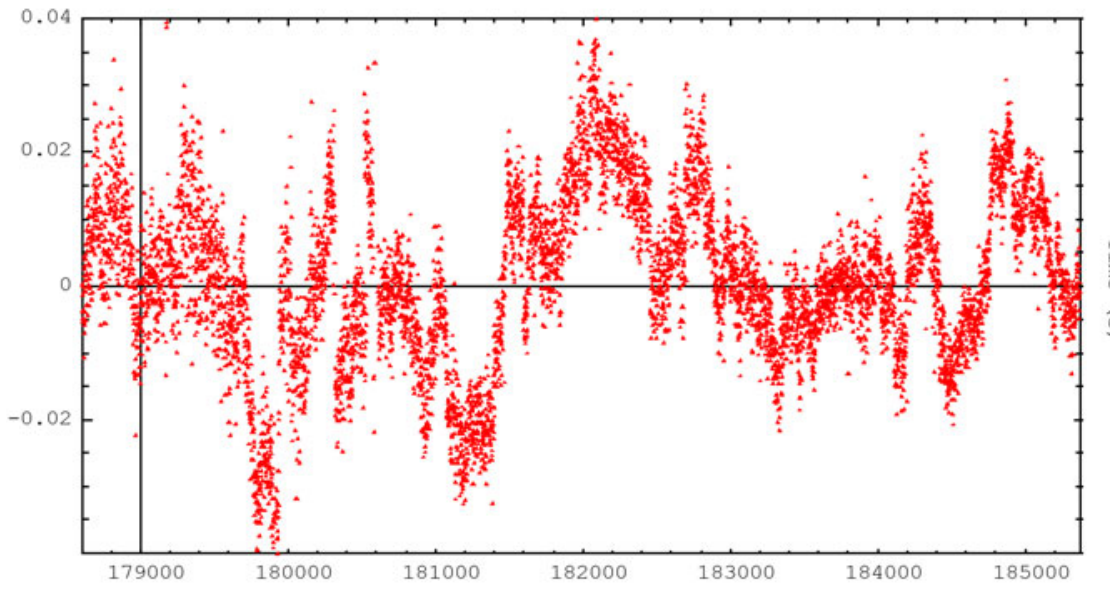

L5 residual (m)

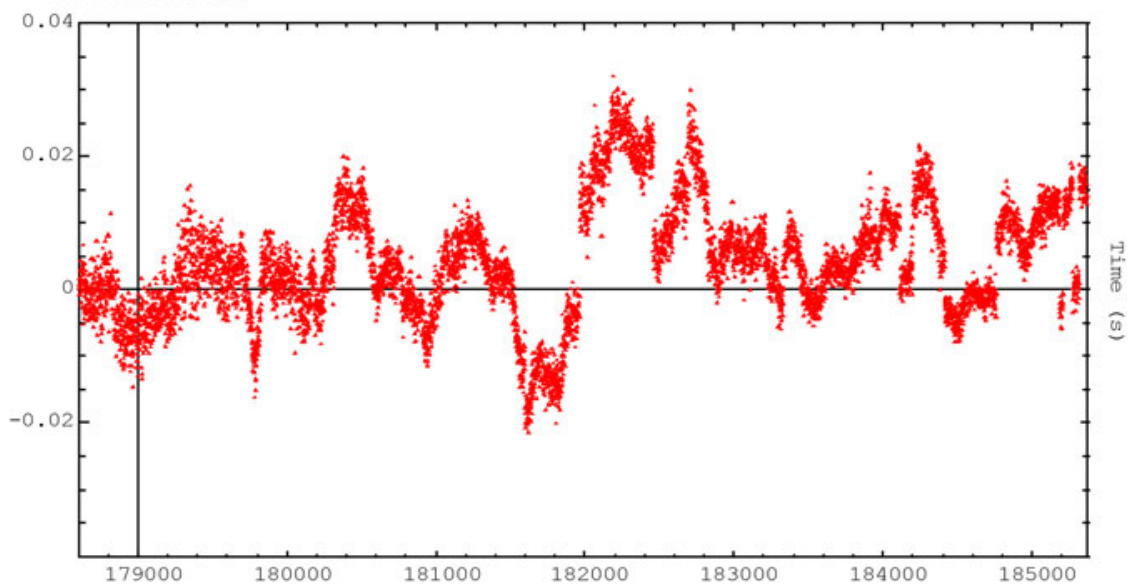

Figure 10. "True" error/residuals in L1 (top), L2 (middle) and L5 (bottom) carrier phases of QZSS MICHIBIKI/J1 in the baseline UNNC01-UNNC25 data set. 
L1 residual $(\mathrm{m})$

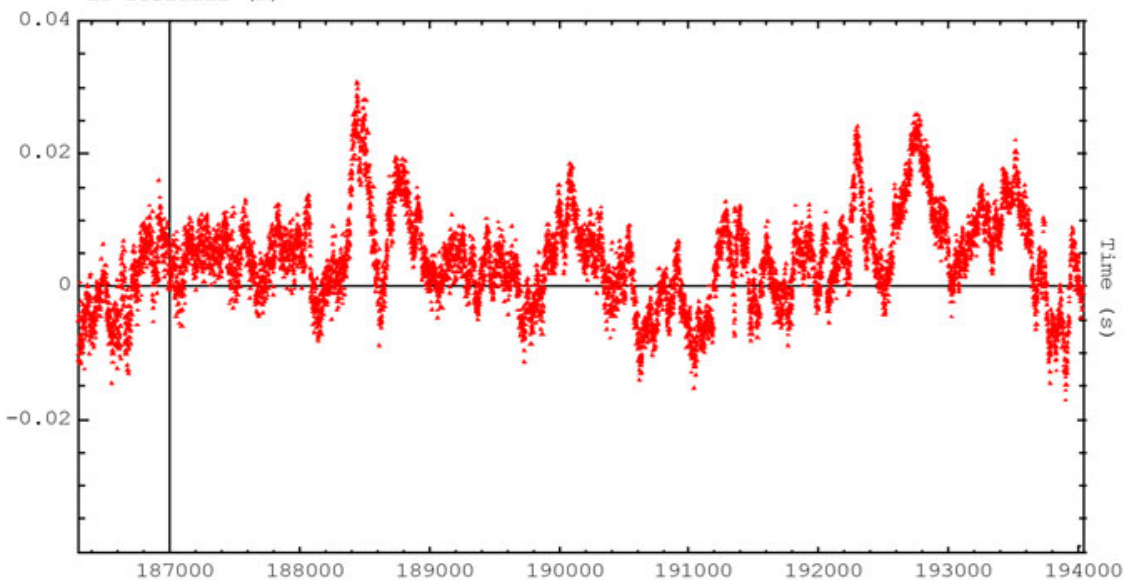

L2 residual (m)

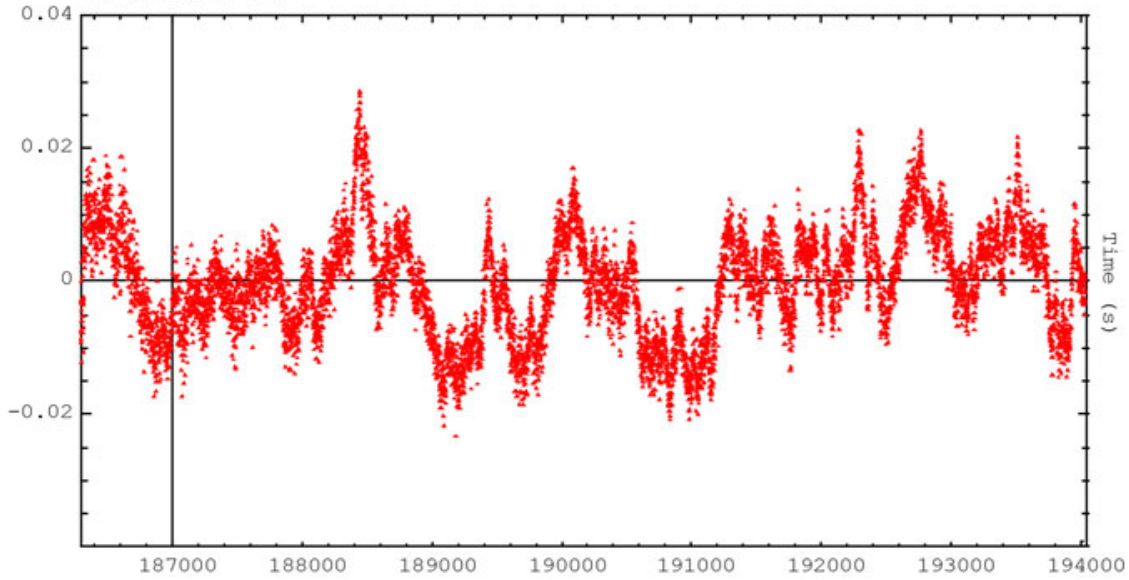

L5 residual (m)

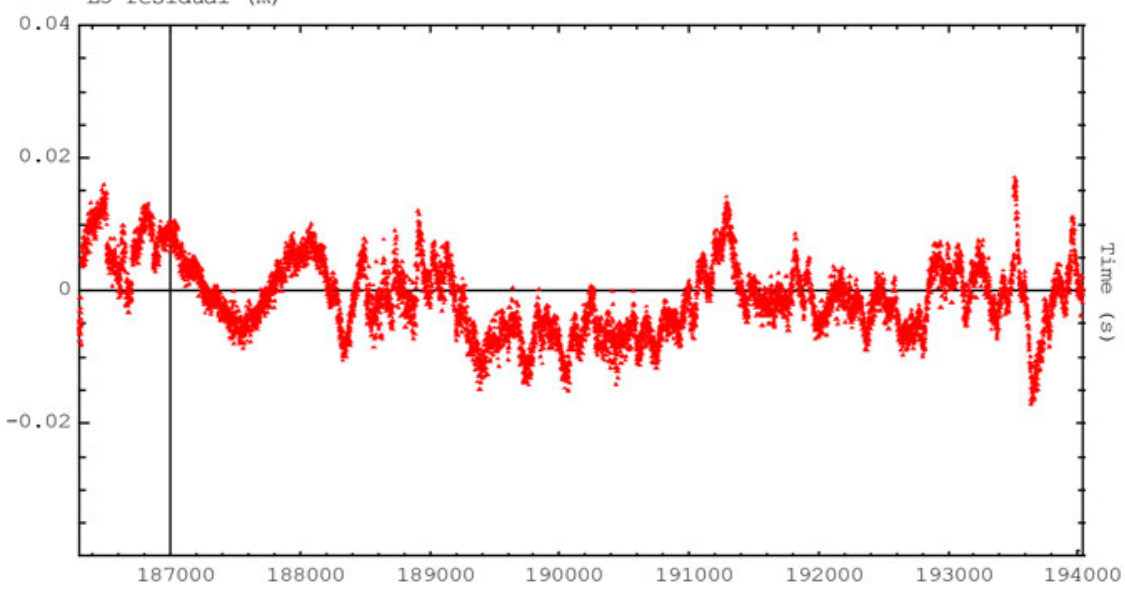

Figure 11. "True" error/residuals in L1 (top), L2 (middle) and L5 (bottom) carrier phases of QZSS MICHIBIKI/J1 in the baseline UNNC01-UNNC26 data set. 
Table 19. The maximum multipath errors in the carrier frequencies of the multipath contaminated GNSS satellites in the baseline UNNC01-UNNC25 data set.

\begin{tabular}{lccc}
\hline GNSS satellite & $\begin{array}{l}\text { L1 maximum } \\
\text { multipath error }(\mathrm{mm})\end{array}$ & $\begin{array}{l}\text { L2 maximum } \\
\text { multipath error }(\mathrm{mm})\end{array}$ & $\begin{array}{l}\text { L5 maximum } \\
\text { multipath error }(\mathrm{mm})\end{array}$ \\
\hline GPS PRN03 & $19 \cdot 5$ & $21 \cdot 3$ & - \\
GPS PRN06 & $18 \cdot 2$ & $23 \cdot 7$ & - \\
GPS PRN27 & $18 \cdot 5$ & $21 \cdot 6$ & $16 \cdot 3$ \\
GLONASS R18 & $15 \cdot 0$ & $21 \cdot 5$ & - \\
GLONASS R19 & $11 \cdot 1$ & $23 \cdot 4$ & - \\
QZSS J1 & $17 \cdot 5$ & $21 \cdot 1$ & $15 \cdot 7$ \\
\hline
\end{tabular}

Table 20. The maximum multipath errors in the carrier frequencies of the multipath contaminated GNSS satellites in the baseline UNNC01-UNNC26 data set.

\begin{tabular}{lccc}
\hline GNSS satellite & $\begin{array}{l}\text { L1 maximum } \\
\text { multipath error }(\mathrm{mm})\end{array}$ & $\begin{array}{l}\text { L2 maximum } \\
\text { multipath error }(\mathrm{mm})\end{array}$ & $\begin{array}{l}\text { L5 maximum } \\
\text { multipath error }(\mathrm{mm})\end{array}$ \\
\hline GPS PRN01 & $14 \cdot 9$ & $12 \cdot 9$ & $11 \cdot 7$ \\
GPS PRN11 & $11 \cdot 9$ & $11 \cdot 5$ & - \\
GLONASS R20 & $9 \cdot 8$ & $18 \cdot 2$ & - \\
QZSS J1 & $14 \cdot 6$ & $11 \cdot 5$ & $13 \cdot 7$ \\
\hline
\end{tabular}

GNSS L2 carrier frequencies show similar maximum multipath errors in the data set. Overall, GLONASS L1 and QZSS L5 carrier frequencies may have the best multipath "immunity" among the current GNSS signals.

6. CONCLUSIONS AND FUTURE RESEARCH. Three data sets have been used to assess the positioning accuracy of the four combinations of selected GNSS constellations, the signal/data quality of their carrier frequencies in single epoch solutions, and the impact of multiple GNSS systems on processing results. The four constellation combinations being tested are i) GPS only, ii) GPS and GLONASS, iii) GPS and QZSS, and iv) GPS, GLONASS and QZSS. One of the data sets was collected in a good (low multipath) environment and the other two data sets were collected in difficult (high multipath) environments. Better than $3 \mathrm{~mm}$ positioning accuracy (in 3D vector) is achieved for all the four GNSS constellation combinations in the data set collected in the good environment. Results of the two difficult-environment data sets show significant increments in the RMS errors of carrier phase measurements of the three GNSS systems and the 3D vector RMS errors of the four constellation combinations when comparing with the results of the data set collected in the good environment. Multipath investigations into the two data sets collected in difficult environments have been carried out; the maximum amplitudes of multipath errors in GNSS carrier frequencies are estimated by using Time Fast Fourier Transform. It is found that the rover station UNNC25 has more severe multipath effect than the rover station UNNC26.

On average of the three data sets, the QZSS L5 carrier frequency has the best performance (i.e., the smallest overall RMS error). GLONASS L1 and QZSS L5 carrier frequencies may have the best multipath "immunity" among the current 
GNSS signals. The effect of combining GLONASS and/or QZSS with GPS is not always the same, sometimes positive but sometimes negative according to the two data sets collected in difficult environments. Positioning accuracy may be reduced when combining with one or more GNSS systems. In "reflective" environments, more satellites may lead to a higher chance of yielding reflected signals and getting more multipath errors. In our tests, multi-GNSS positioning accuracy is reduced when there are severe multipath errors (see the results of the UNNC01-UNNC25 data set; Table 9). In this case study carried out at Ningbo, the benefit of QZSS may not be as significant as in Japan and Australia because the current single QZSS satellite MICHIBIKI can only be observed at high elevation angles and at about the zenith in the two countries (see Figures 2, Figure 8 and Figure 9).

Further research will be carried out to investigate the impact of combining Galileo and BeiDou with the three selected GNSS constellations in this paper on high-precision positioning performance and the data quality of the new signals. Moreover, as a finding of this paper is that the impact of combining GNSS systems is not always positive, it is worth investigating sophisticated satellite selection algorithms and stochastic models and in preparation for the era of so many redundant GNSS measurements.

\section{ACKNOWLEDGMENTS}

This paper is part of the project "Exploiting the use of QZSS and Multi-GNSS for navigational and high precision positioning applications and their performance assessment (EQUATOR)" in the JAXA's Multi-GNSS Joint Experiment.

\section{REFERENCES}

Clark, S. (2013) Japan to build fleet of navigation satellites. Spaceflight Now, 2013-04-04. http://www.spaceflightnow.com/news/n1304/04qzss/ (Retrieved on 2014-03-30).

Lau, L. (2004) Investigations into Multipath Effects on GNSS Multiple-Frequency Single Epoch High Precision Positioning. Proceedings of ION GNSS 2004, Long Beach, California, 21-24 September 2004.

Lau, L. and Cross, P. (2006) A New Signal-to-Noise-Ratio Based Stochastic Model for GNSS HighPrecision Carrier Phase Data Processing Algorithms in the Presence of Multipath Errors. Proceedings of ION GNSS 2006, September 26-29, Fort Worth Convention Center, Fort Worth, Texas.

Lau, L. and Cross, P. (2007a). Phase Multipath Mitigation Techniques for High Precision Positioning in All Conditions and Environments. Journal of Navigation, 60(3), pp. 457-482.

Lau, L. and Cross, P. (2007b) Development and Testing of a New Ray-Tracing Approach to GNSS CarrierPhase Multipath Modelling. Journal of Geodesy, 81(11), 713-732.

Lau, L. and Cross, P. (2008) Tests with Practical Multivariate Statistical Multipath Detection Methods Using Multiple-Frequency GNSS Phase Data. Proceedings of International Symposium on GPS/GNSS 2008, 11-14 November, Tokyo, Japan, pp. 990-1004.

Li, B., Feng, Y., Shen, Y. (2010) Three carrier ambiguity resolution: Distance-independent performance demonstrated using semi-generated triple frequency GPS signals. GPS Solutions. 14(2): pp. 177-184.

O'Keefe, K., Petovello, M., Cao, W, Lachapelle, G., Guyader, E. (2009) Comparing Multicarrier Ambiguity Resolution Methods for Geometry-Based GPS and Galileo Relative Positioning and Their Application to Low Earth Orbiting Satellite Attitude Determination, International Journal of Navigation and Observation, Article ID 592073, 15 pages, doi:10.1155/2009/592073

Rizos, C. (2008) Multi-Constellation GNSS/RNSS From the Perspective of High Accuracy Users in Australia. Journal of Spatial Science, 53(2). DOI:10.1080/14498596.2008.9635149

RTKLIB (2014) RTKLIB: An Open Source Program Package for GNSS Positioning. http://www.rtklib.com. Accessed 18 July 2014

Schönemann, E., Becker, M., and Springer, T. (2011) A new Approach for GNSS Analysis in a Multi-GNSS and Multi-Signal Environment. Journal of Geodetic Science, 1(3), pp. 204-214. DOI:10.2478/v10156-010-0023-2. 